\title{
Adsorption of Pharmaceutical Contaminants from Aqueous Solutions Using N,0-Carboxymethyl Chitosan/Polyethylene Oxide (PE0) Electrospun Nanofibers
}

\author{
Amna Hassan Issa Khierallah¹, Ilse Ileana Cardenas Bates ${ }^{1}$, Bruno Chabot ${ }^{1}$, André Lajeunesse ${ }^{1,2,3}$ \\ ${ }^{1}$ Institut d’Innovations en Écomatériaux, Écoproduits et Écoénergies (I2E3), Université du Québec à Trois-Rivières, Trois-Rivières \\ (QC), Canada \\ ${ }^{2}$ Département de Chimie, Biochimie et Physique, Université du Québec à Trois-Rivières, Trois-Rivières (QC), Canada \\ ${ }^{3}$ Centre de Recherche en Écotoxicologie du Québec (EcotoQ), Québec (QC), Canada \\ Email: andre.lajeunesse@uqtr.ca
}

How to cite this paper: Khierallah, A.H.I., Bates, I.I.C., Chabot, B. and Lajeunesse, A. (2021) Adsorption of Pharmaceutical Contaminants from Aqueous Solutions Using N,O-Carboxymethyl Chitosan/Polyethylene Oxide (PEO) Electrospun Nanofibers. Journal of Materials Science and Chemical Engineering, 9, 15-38.

https://doi.org/10.4236/msce.2021.911003

Received: September 3, 2021

Accepted: November 22, 2021

Published: November 25, 2021

Copyright (c) 2021 by author(s) and Scientific Research Publishing Inc. This work is licensed under the Creative Commons Attribution International License (CC BY 4.0).

http://creativecommons.org/licenses/by/4.0/ (c) (i) Open Access

\begin{abstract}
Residues of pharmaceutical and direct metabolites discharged into the aquatic environment have become a challenge for wastewater treatment facilities due to their increase in concentration and their different physicochemical properties. These emerging contaminants are daily detected in surface water and wastewater discharged by municipalities. To remediate the contaminated water, various methods are currently used including primary, secondary, and tertiary advanced treatments. However, some economic and environmental limitations have forced the scientific community to develop alternative disinfection processes to purify wastewater. As such, the adsorption strategy represents a "green" low-cost and effective solution to remove pollutants from water. In this study, a nanomaterial made of N,O-carboxymethyl chitosan (N,O-CMCS) was prepared using chitosan (CS) and monochloroacetic acid under various conditions. N,O-CMCS electrospun was synthetized with the copolymer polyethylene oxide (PEO) to create nanofiber membranes showing a better specificity toward diversified contaminants depending on the $\mathrm{pH}$ of medium. The developed adsorbent was used to remove fluoxetine (FLX) from aqueous solutions. The new nanomaterial was characterised using FTIR, NMR, and SEM techniques. Sorption batch tests were carried out using high-performance liquid chromatography and ultraviolet diode array detector (HPLC-UV DAD) under controlled $\mathrm{pH}$ experimental conditions to determine the contaminant removal capacity of the nanomaterial. The prom-
\end{abstract}


ising adsorption results obtained with N,O-CMCS/PEO nanofibers are among the best ones obtained so far in comparison to other commercial and synthetized adsorbents tested for FLX's adsorption. Kinetic experiments were also performed to investigate effects of contact times on the FLX adsorption. Experimental results were fitted to both common kinetic models pseudo-first and second order. The latter kinetic model described the best the sorption on surface. It revealed a possible chemisorption mechanism with electrostatic bounding for N,O-CMCS/PEO nanofibers.

\section{Keywords}

N,O-Carboxymethyl Chitosan, Electrospinning, Nanofibers, Adsorption, Pharmaceuticals

\section{Introduction}

The contamination of natural resources such as water remains one of the most challenging issues of modern-day society. Worldwide water contamination by chemicals is especially of concern [1]. Even though most of these contaminants are detected at very low concentrations (ng/L to $\mu \mathrm{g} / \mathrm{L}$ ), many molecules (and/or their treatment by-products) possess biological activity. They are daily discharged into water bodies and may cause severe environmental issues (e.g. detrimental effects to our natural water resources and aquatic organisms) if they are not properly removed [2] [3]. Among listed contaminants, pharmaceutical products are now recognized as primary polluters retrieved in marine environments and ecosystems mainly after human or animal excretion [4] [5] [6]. These pollutants are represented by a wide array of substances that include both non-prescription and prescription drugs [7]. They are part of different classes (e.g. analgesics, antibiotics, $\beta$-blockers, lipid regulators, antidepressants, contraceptives, synthetic and natural hormones) [8] [9]. In addition, industrial by-products, as well as some hospital effluents have been reported in literature as major contamination sources since they are released at higher concentrations in municipal effluents [10]. Unfortunately, limited removal rates are frequently observed in wastewater treatment plants (WWTPs) for pharmaceuticals residues [11] [12].

Since traditional water and wastewater treatment systems are facing difficulties to provide an effective barrier against recalcitrant compounds, advanced treatment strategies need to be developed [13]. As such, membrane filtration, advanced oxidation processes (AOPs), and UV irradiation are examples of processes that have the potential to improve the water remediation [14]. Despite their effectiveness in removing pharmaceuticals residues, some of these may not be suitable due to "high-unit-volume" treatment costs. Additional efforts on the extraction methodologies are therefore required, especially with emerging nano- 
technologies [13]. In this way, adsorption of contaminants is now recognized as a promising and efficient separation technique for wastewater treatment [15]. The adsorption phenomenon on surface's materials can be described using different theoretical developed models of varied complexity. Thus, the uptake rate can be determined with pseudo-first-order (PFO) and pseudo-second-order (PSO) models, while mechanisms of sorption can be elucidated using well-known and recognized isotherms models (e.g. Langmuir, Freundlich, etc.) [16].

Among existing adsorbent materials, zeolites [17] and activated carbon (AC) [18] [19] [20] were largely studied for treating wastewater due to their high performance. However, a longer recycling time and expensive regeneration procedures have made them difficult to use on a regular basis. To overcome such drawbacks, a considerable work was spent in developing effective and environmentally friendly adsorbents based on available low-cost natural polymeric materials [10]. Accordingly, different biomaterials were found to be effective for the elimination of contaminants from aqueous effluent.

In the last decade, biomaterials have received a lot of attention because of their biodegradable and non-toxic composition [21]. The naturally abundant polysaccharide chitosan (CS) produced from a deacetylation of chitin, has been used in several adsorption applications [15]. However, its high viscosity, crystallinity, as well as its poor mechanical strength, limited solubility and instability in acidic medium have restricted its usefulness as adsorbent [22] [23] [24]. Hence, chemical modifications of CS are performed to improve some properties (e.g. solubility, antimicrobial behavior, and ability to interfere with other compounds) [25] [26]. A chemical modification may also be attempted in order to gain more specificity and a sorption versatility toward contaminants, depending on the grafted chemical functionalities on the surface of CS [27].

One well-known modified CS derivative is N,O-carboxymethyl chitosan (N,O-CMCS) [27] [28]. This modified biopolymer is synthetized following an alkalization and a nucleophilic substitution (SN2) reaction using monochloroacetic acid $\left(\mathrm{ClCH}_{2} \mathrm{COOH}\right)$ [29] [30]. The medium temperature and reagents of the reaction (including their stoichiometry) influence both the substitution of the CMCS (N- and/or O-) and its ratio of substitution [31] [32]. Aside from its high viscosity and hydrodynamic volume, CMCS has unique chemical, physical and biological properties [33]. This modified biopolymer enables low toxicity, biodegradability, biocompatibility and high ability to form films, fibers, and hydrogels [34]. Some chemical modifications achieved on CS's surface were exploited in order to increase its water solubility and broaden its range of applications [35] [36] [37]. Other carboxymethyl derivatives having different properties were reported elsewhere (O-CMCS, N,O-CMCS, N-CMCS and N-succinyl chitosan (NSC)) [38].

Synthetized nanomaterials are of great interest for a variety of applications due to their sought characteristics, such as high specific surface area and porosity [26]. In this way, electrospinning has gained popularity because of its ability to produce polymer nanofibers with diameters varying from several micrometers 
to tens of nanometers [39] [40]. During electrospinning, a high voltage is applied to generate an electrically charged jet of a polymer previously dissolved in solution. The elongated jet is then collected on a metallic surface (target electrode) upon the evaporation of the used solvent producing nanofibers as a nonwoven mat. The formation of electrospun nanofibers from polymer solutions has been extensively studied in terms of voltage, tip-to-collector distance, polymer solution extrusion rate, and polymer solution properties [41].

Until now, a wide range of harmful environmental contaminants such as heavy metals, dye materials, and a few pharmaceuticals residues have been adsorbed by CS nanofiber membranes [42] [43] [44]. Therefore, the use of membranes made of N,O-CMCS could represent an interesting alternative method to purify pharmaceutical residues from wastewater. To the best of our knowledge, there is no application reported yet on modified N,O-CMCS electrospun nanofibers used as adsorbent to extract pharmaceuticals residues from wastewater, especially the antidepressant fluoxetine (FLX) largely prescribed around the world by physicians to treat depression. This paper aims at the development of N,O-CMCS/PEO electrospun nanofibers, with a focus on the fundamentals of their manufacturing (e.g. chemical synthesis, characterization, electrospinning conditions). In addition, some batch tests are performed to determine the best adsorption conditions of FLX in aqueous solution. Finally, a kinetics study is also provided as complementary information to better understand the adsorption behavior of the synthetized membranes.

\section{Materials and Methods}

\subsection{Materials}

A low molecular weight chitosan (CS) (MW 50,000 - 190,000 g/mol, 75\% - 85\% deacetylated) was purchased from Sigma-Aldrich (Reykjavik, Iceland). Polyethylene oxide (PEO) with an average molecular weight of 900,000 g/mol (Sigma-Aldrich, St. Louis, MO, USA) was used as a co-spinning agent. Chloroacetic acid was purchased from Sigma-Aldrich, sodium hydroxide $(\mathrm{NaOH})$, acetic acid $\left(\mathrm{CH}_{3} \mathrm{COOH}\right)$, sodium carbonate $\left(\mathrm{Na}_{2} \mathrm{CO}_{3}\right)$, isopropanol, and ethanol were also used for experimentations. All chemicals were analytical grades. Fluoxetine hydrochloride (FLX) (CAS 56296-78-7) from Sigma-Aldrich (Oakville, ON, Canada) was used for the adsorption batch test as a model contaminant. Methanol (HPLC grade), acetonitrile (HPLC grade), O-phosphoric acid (HPLC grade; 85 wt\%), and glacial acetic acid ACS reagent (99.7\%) were purchased from Fisher Scientific (Ottawa, Ontario, Canada). Deionized water was used for experiments (Siemens Ultra Clear RO).

\subsection{Methods}

\subsubsection{Preparation of $\mathrm{N}, \mathrm{O}-\mathrm{CMCS}$}

An adapted methodology was used for the synthesis of N,O-CMCS by alkalization followed by carboxylation [45]. CS (2.00 g) was mixed in $20 \mathrm{~mL}$ of a sodium 
hydroxide (20\%) solution and stirred at room temperature (RT) for $12 \mathrm{~h}$. The resulting CS of higher degree of deacetylation was separated by filtration. Next, $15 \mathrm{~mL}$ of isopropanol was added to the previously treated CS. Then, monochloroacetic acid $(1.43 \mathrm{~g})$ dissolved in isopropanol $(10 \mathrm{~mL})$ was slowly added dropwise into the treated CS isopropyl alcohol solution. The mixture was agitated for an additional $30 \mathrm{~min}$. The flask was then put into a heated oil bath and stirred for $4 \mathrm{~h}$. Then, the content was poured into a $50 \mathrm{~mL}$ beaker. Under continuous stirring condition, acetic acid (50\%) was slowly added until the $\mathrm{pH}$ value reached 9. The product was in its salt-based form (N,O-CMCS-Na) due to the alkaline reaction medium. Finally, the reaction mixture was filtered, and the solid product was rinsed 3 times with a $200 \mathrm{~mL}$ ethanol solution, then once with absolute ethanol. The resulting solid was subsequently dried in an oven $\left(50^{\circ} \mathrm{C}\right)$ for three days. After, $1 \mathrm{~g}$ of N,O-CMCS-Na was suspended in $80 \%$ ethyl alcohol aqueous solution $(100 \mathrm{~mL})$, and then $10 \mathrm{~mL}$ of hydrochloric acid (37\%) was added dropwise and stirred for $30 \mathrm{~min}$ to get the neutralized form. The resulting solid N,O-CMCS was filtered and rinsed using ethanol (70\% - 90\%) prior being dried out under vacuum overnight at RT [20].

\subsubsection{Characterization of $\mathrm{N}, \mathrm{O}-\mathrm{CMCS}$}

The Fourier transformed infrared (FT-IR) and proton nuclear magnetic resonance ( $\left.{ }^{1} \mathrm{H}-\mathrm{NMR}\right)$ spectroscopy were used to confirm the addition of carboxymethyl groups on the CS amino and primary hydroxyl sites of the CS. Analyses were performed on an FT-IR spectrometer (FTIR Thermo iS10) at wavenumbers ranging from 600 to $4000 \mathrm{~cm}^{-1}$. ${ }^{1} \mathrm{H}-\mathrm{NMR}$ spectra of CS were obtained in $\mathrm{D}_{2} \mathrm{O}$, and $\mathrm{N}, \mathrm{O}-\mathrm{CMCS}$ in $\mathrm{D}_{2} \mathrm{O} / \mathrm{HCl}(100: 1 \mathrm{v} / \mathrm{v})$ using an NMR spectrometer (OXFORD NMR) under a static magnetic field of $200 \mathrm{MHz}$.

To determine the zeta potential (ZP), a $1 \mathrm{M}(10 \mathrm{~mL})$ solution of N,O-CMCS was dissolved in distilled water for $1 \mathrm{~h}$ with moderate shaking at room temperature. $\mathrm{NaOH}(0.01 \mathrm{M})$ was used to neutralize the $\mathrm{pH}$ of the solution. The zeta potential in solution was determined using a ZetasizerNano (Malvern Instruments Ltd., model ZEN 3600).

\subsubsection{Electrospinning, Preparation of N,O-CMCS and PEO Solutions}

Stock solutions of N,O-CMCS and PEO were prepared in distilled water at three specific concentrations: $2.5,3.3$ and $8.0 \mathrm{wt} \%$ for N,O-CMCS, and 1.5, 3.0 and 8.0 $w t \%$ for PEO. To ensure a full and homogeneous dissolution, both solutions were kept under agitation at RT (e.g. 2 h, N,O-CMCS; 20 h PEO). Then, appropriate amounts of $\mathrm{N}, \mathrm{O}-\mathrm{CMCS}$ and $\mathrm{PEO}$ were mixed at various ratios to prepare electrospinning solutions. Electrospinning solutions used in this study are summarized in Table 1.

All electrospinning solutions were magnetically stirred for $2 \mathrm{~h}$, then transferred in an ultrasonic bath for 15 min to remove air bubbles. Finally, the mixture was rested for $3 \mathrm{~h}$ before being used in the electrospinning setup. The $\mathrm{N}, \mathrm{O}-\mathrm{CMCS} / \mathrm{PEO}$ solution was poured into an electrospinning plastic syringe or 
Table 1. Electrospinning solutions prepared at various weight ratios for experimentations.

\begin{tabular}{cc}
\hline Electrospinning solution & Weight \% ratio (CMCS:PEO) \\
\hline 1 & $2: 1$ \\
2 & $1: 3$ \\
3 & $3: 1$ \\
4 & $3: 4$ \\
5 & $1: 4$ \\
6 & $4: 3$ \\
7 & $4: 1$ \\
\hline
\end{tabular}

kept in a refrigerator at $4^{\circ} \mathrm{C}$.

\subsubsection{Electrospinning Parameters}

A syringe pump device (KD Science, model 100), a high-voltage power supply (Gamma High Voltage Research USA), and a metallic wireframe as a collector were part of the electrospinning system. For the conservation and stabilization of the membranes, two laboratory ovens (Fisher Scientific IsotempOven, Thermo Scientific HERAThermOven) were used. A schematic diagram of the electrospinning set-up used for the membrane preparation is depicted in Figure 1. Each electrospinning solution (Table 1) was poured into a $5 \mathrm{~mL}$ syringe mounted with a 20-gauge needle and attached to a syringe pump providing a slow and steady flow rate of liquid $(0.4 \mathrm{~mL} / \mathrm{h})$. A distance $(6-8 \mathrm{~cm})$ was set between the tip of the needle and the collector. A metallic frame was used for the collector. The voltage used ranged between 10 and $15 \mathrm{kV}$. Various electrospinning conditions were attempted to obtain an optimal jet as well (stable with minimal drop projections) and beadless nanofibers mats by varying the flow rate, distance, and electrical current. Electrospinning was carried out in a tailor-made enclosure, at RT and relative humidity ranging between $30 \%-50 \%$. The nanofibrous mat was removed from the frame at the end of the electrospinning process and dried for $24 \mathrm{~h}$ in an oven at $80^{\circ} \mathrm{C}$.

\subsubsection{Stabilization of Nanofibers}

$\mathrm{N}, \mathrm{O}-\mathrm{CMCS} / \mathrm{PEO}$ nanofibers are soluble in water following the electrospinning process due to ionizable chemical functionalities of the material. After electrospinning, the nanofiber mat was dried overnight in an oven at $80^{\circ} \mathrm{C}$ to remove residual solvent. A stabilization cycle was then completed by soaking resulting membranes in $\mathrm{Na}_{2} \mathrm{CO}_{3}(0.1 \mathrm{M})$ at $\mathrm{RT}$ for $3 \mathrm{~h}$ [43]. Finally, to improve the nanofiber mat stability in aqueous media, a heat treatment at $140^{\circ} \mathrm{C}$ for $30 \mathrm{~min}$ was applied. The material stability was determined by an immersion in water for up to $6 \mathrm{~h}$. Effects of water on nanofiber structure and morphology were studied by SEM images. 


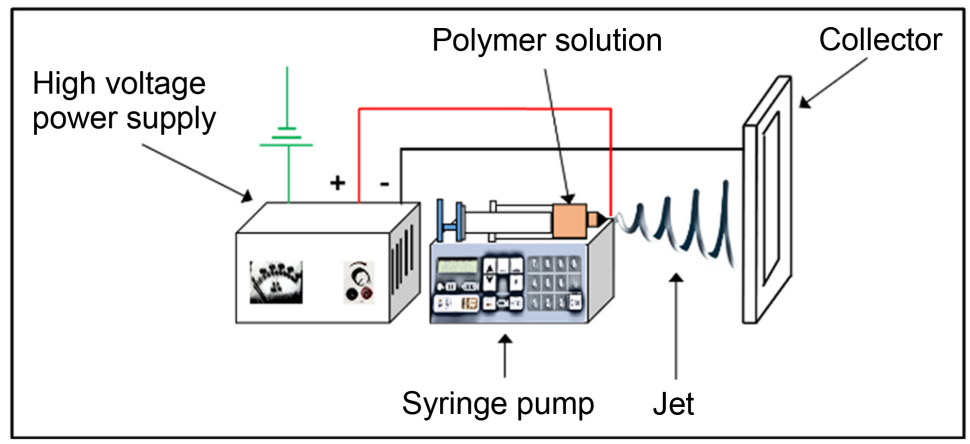

Figure 1. Schematic representation of the electrospinning setup.

\subsubsection{Characterization of Nanofibers}

The degree of substitution (DS) of the sample was calculated using a potentiometric titration method [46]. Briefly, dried N,O-CMC (0.20 g) was dissolved in $0.1 \mathrm{M}$ hydrochloric acid solution $(20 \mathrm{~mL})$. Methyl orange was used as indicator for the end-point determination. A standard $0.1 \mathrm{M}$ sodium hydroxide solution was used during titration [31] [46]. The cumulative DS of the sample was determined using Equations (1) and (2):

$$
\begin{aligned}
\mathrm{DS} & =\frac{161 A}{M_{\mathrm{CMCS}}}-58 A \\
A & =V_{\mathrm{NaOH}} \cdot C_{\mathrm{NaOH}}
\end{aligned}
$$

where $M_{\mathrm{CMCS}}$ is the mass of CMCS (g), $V_{\mathrm{NaOH}}$ and $C_{\mathrm{NaOH}}$ are representing respectively the volume and molar concentration $(\mathrm{M})$ of $\mathrm{NaOH}$, and finally 161 and 58 are associated to the molecular weights of the chitosan (glucosamine) and the CMCS group [31].

Morphologies of both nanofibers CS/PEO and N,O-CMCS/PEO were assessed using a scanning electron microscope (SEM) (Hitachi SU1510 Scanning Electron Microscope). The average diameter of electrospun nanofibers was estimated using SEM images and Image J software. In order to obtain an average value, the diameter of 50 nanofibers collected on three separate images was calculated (e.g. total of 150 nanofibers per sample).

Some infrared (FT-IR) spectra analyses of the electrospun nanofiber mats were performed using a Fourier transform infrared spectrometer (Nicolet iS10, Thermo Scientific) in the 400 to $4000 \mathrm{~cm}^{-1}$ wavenumbers range. In addition, ${ }^{1} \mathrm{H}-\mathrm{NMR}$ spectra of CS and N,O-CMCS in $\mathrm{D}_{2} \mathrm{O} / \mathrm{DCl}$ were recorded using a 200 $\mathrm{MHz}$ NMR spectrometer (Varian).

\subsubsection{Batch Adsorption Procedure}

The adsorption of FLX by the electrospun nanofibrous mat was carried out in batch mode. A $25 \mathrm{mg}$ sample of the membrane was inserted into one Erlenmeyer flask containing $50 \mathrm{~mL}$ of an FLX solution (50 ppm) and 5\% of methanol. The flask was then agitated on an orbital shaker (ORBIT Environ-shaker, Lab-Line) at RT. Before insertion of the membrane into the solution, an aliquot of $500 \mu \mathrm{L}$ was sampled to determine the initial FLX concentration. Batch tests were con- 
ducted over a period of $150 \mathrm{~min}$ to ensure that equilibrium was achieved prior to the collection of a $500 \mu \mathrm{L}$ aliquot. The adsorption capacity at time $t\left(Q_{t}\right)$ was determined using the following Equation (3):

$$
Q_{t}=\frac{\left(C_{0}-C_{e}\right) V}{m}
$$

where $C_{e}$ is the concentration of the contaminant (ppm) at time $t(\mathrm{~min}), C_{0}$ is the initial concentration of contaminants (ppm), $V$ is the volume of the solution (L), and $m$ is the mass of adsorbents $(\mathrm{g})$.

In order to determine the residual concentration of FLX in water samples during batch adsorption tests, a high-performance liquid chromatography (HPLC) system (Shimadzu Prominence I-series) coupled with a diode array detector (DAD) was used. The chromatographic separation was achieved using a C18 reverse-phase column (XB-C18, $100 \AA, 150 \times 3 \mathrm{~mm}, 2.6 \mu \mathrm{m}$ particle size, Phenomenex, Kinetex $\left.{ }^{\otimes}\right)$. The residual concentration of FLX in aqueous solution was determined by HPLC-UV DAD according to a method developed by $\mathrm{Ca}$ miré et al. 2018 [44].

\subsubsection{Kinetic Tests}

Kinetic curves were obtained by collecting medium samples $(500 \mu \mathrm{L})$ at predetermined periods $(0,5,10,15,20,25,30,40,50,60,75,90,120$, and $150 \mathrm{~min})$. Tests were carried out at RT with an initial FLX concentration of $50 \mathrm{ppm}$. Concentrations of FLX in aqueous phase were determined using an HPLC-UV DAD system. All tests were performed in triplicate to provide mean and standard deviation values.

Adsorption kinetic models are used to characterize the adsorption process (e.g. the movement of the adsorbate to the adsorbent's external surface, the internal diffusion of the adsorbate to the active sites, and the real sorption to the adsorbent's external surface) [47] [48]. Two models are mostly used in kinetics studies by researchers. Hence, it was decided to use nonlinear forms of pseudo-first-order (PFO) (Equation (4)) and pseudo-second-order (PSO) (Equation (5)) models in order to get the best-fit experimental data.

$$
\begin{gathered}
Q_{t}=Q_{e}\left(1-\exp ^{-k_{1} t}\right) \\
Q_{t}=\frac{k_{2} Q_{e}^{2} t}{1+k_{2} Q_{e} t}
\end{gathered}
$$

where $Q_{e}$ is the amount adsorbed $(\mathrm{mg} / \mathrm{g})$ at equilibrium, $Q_{t}$ is the amount adsorbed $(\mathrm{mg} / \mathrm{g})$ at time $t(\mathrm{~min}), k_{1}$ is the PFO adsorption rate constant $\left(\mathrm{min}^{-1}\right)$, and $k_{2}$ is the PSO adsorption rate constant ( $\mathrm{g} / \mathrm{g} \mathrm{min}$ ).

Kinetic models are typically used to examine the mechanism involved during the adsorption process, as well as the location at the surface of adsorption, the chemical reaction involved, and/or the processes of diffusion. As the process of prevalence, the PFO model assumes a physical adsorption, while a chemical adsorption is inferred by the PSO model [49]. Kinetic parameters (maximum adsorption potential and kinetic constant) were determined for both models using 
software: the kinetic equation solve feature for Microsoft Excel, and nonlinear regression analysis (MATLAB).

\section{Results and Discussion}

\subsection{Characterization Techniques of CS and N,O-CMCS}

$\mathrm{N}, \mathrm{O}-\mathrm{CMCS}$ was synthesized by alkalization followed by carboxylation as shown in Scheme 1. First, CS was treated with an alkaline solution of isopropanol using $\mathrm{NaOH}$, which acted as a swelling agent. The latter enables the penetration of the relatively unreactive CS polymer. Then, the CS was treated with monochloroacetic acid to generate N,O-CMCS prior to its neutralization with $\mathrm{HCl}(37 \%)$ [28] [35]. Infrared (IR) and ${ }^{1} \mathrm{H}-\mathrm{NMR}$ spectroscopy provided evidences of the successful carboxymethylation and the presence on resulting spectra of distinctive CS and CMCS functional groups [35]. As reported in the literature, this reaction does not go to completion and certain hydroxyl and amino moieties remain unsubstituted [39]. Furthermore, it must be taken into account that if CS is not fully deacetylated, certain units of glucosamine and acetylglucosamine from the partial deacetylation of the parent chitin may also interfere with the reaction [50] [51]. According to Du and Hsieh (2008), the DS and yield of CMCS should be higher with longer reaction times of both alkalization $(2-12 \mathrm{~h}$ ) and carboxylation $(2-5 \mathrm{~h})$ [31]. However, they only improved at higher temperature of alkalization [31]. Based on these findings, we determined the best chemical reaction conditions and optimized the chemical synthesis of N,O-CMCS with DS value of $1.15(\geq 85 \%)$. The carboxylation and alkalization were both conducted at $60^{\circ} \mathrm{C}$. During the carboxylation reaction $(4 \mathrm{~h})$, no additional gain was observed in terms of DS at extended time. However, increasing the reaction time of the alkalization from $2 \mathrm{~h}$ to $12 \mathrm{~h}$ had a tremendous impact on the DS. As expected, the resulting $\mathrm{N}, \mathrm{O}-\mathrm{CMCS}$ biomaterial is soluble in distilled water at $60^{\circ} \mathrm{C}[52]$ [53] [54].

\subsubsection{Infrared (FT-IR) Analysis}

Infrared spectra of CS and N,O-CMCS are depicted in Figure 2. As shown, additional bands are well supporting the chemical structure of N,O-CMCS (DS 1.15). The broad band at $3301 \mathrm{~cm}^{-1}$ (axial stretching of the $\mathrm{O}-\mathrm{H}$ and $\mathrm{N}-\mathrm{H}$ bonds secondary amine) is present in FT-IR spectra (Figure 2(b)); this evidence suggests the formation of the modified compound at $\mathrm{NH}$ position of the CS. In
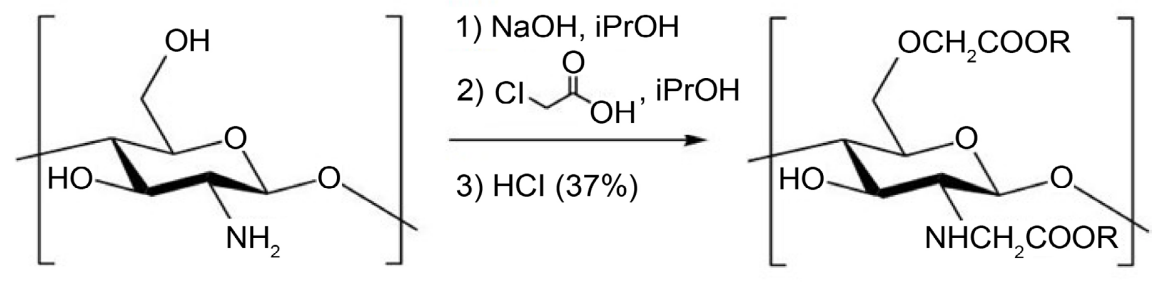

$$
\mathrm{R}=\mathrm{H} \text { or } \mathrm{Na}
$$

Scheme 1. Synthetic route of N,O-carboxymethyl chitosan. 


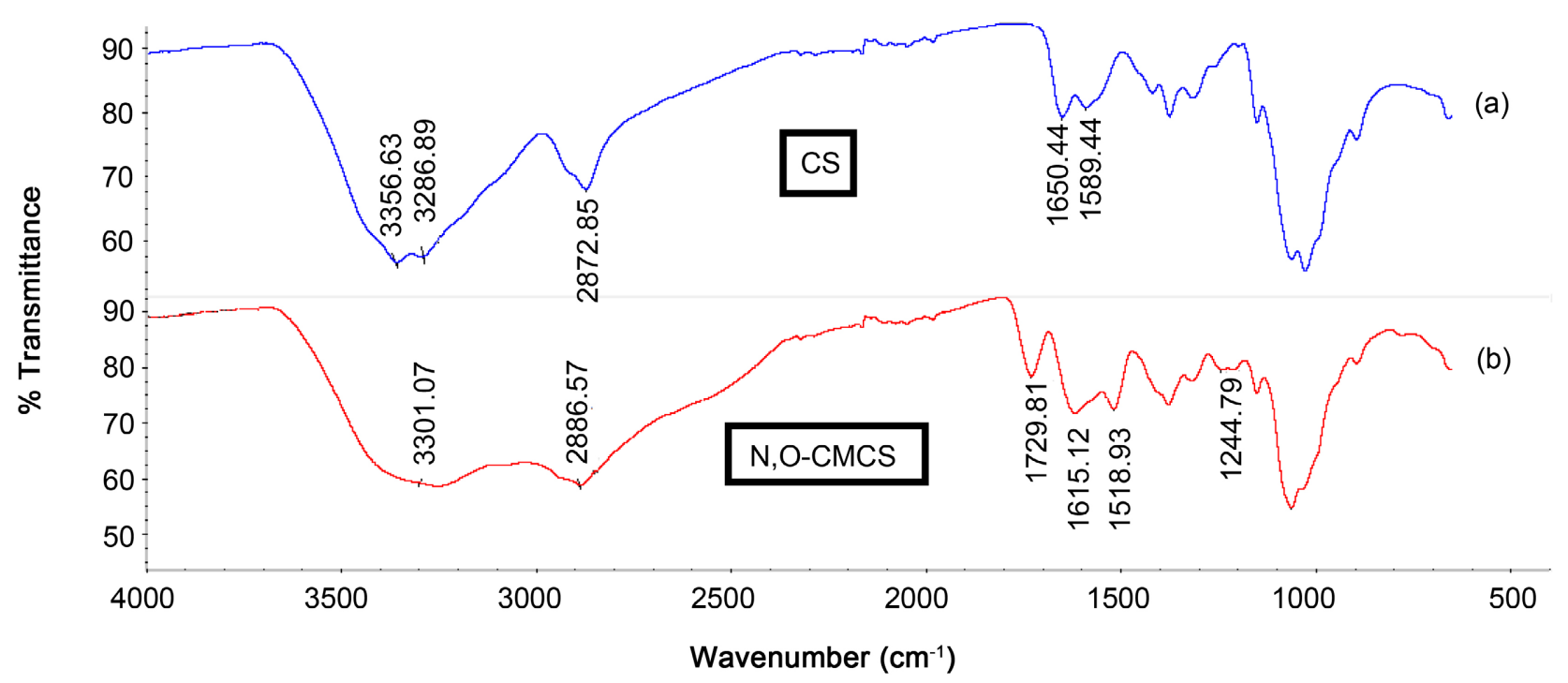

Figure 2. FTIR spectra of CS (a), and N,O-CMCS (DS 1.15) (b).

addition, the stretching vibration of $\mathrm{C}-\mathrm{O}$ located in $\mathrm{CH}_{2} \mathrm{COOH}$ group can be associated to peaks $1250 \mathrm{~cm}^{-1}$ and $1245 \mathrm{~cm}^{-1}$. The peak at $2887 \mathrm{~cm}^{-1}$ corresponds to the axial stretching of the C-H bonds, and the peak $1730 \mathrm{~cm}^{-1}$ is related to the carbonyl group $\mathrm{C}=\mathrm{O}$ from the newly formed $\mathrm{COOH}$ groups, which was not part of the initial CS spectrum. Bands at $1150-897 \mathrm{~cm}^{-1}$ of C-O and C-O-C appear in all spectra. Characteristic bands that belong to CS are also identified: $3357 \mathrm{~cm}^{-1}$ and $3287 \mathrm{~cm}^{-1}$ (O-H and $\mathrm{N}-\mathrm{H}$ bonds), $1650 \mathrm{~cm}^{-1}$ and $1589 \mathrm{~cm}^{-1}\left(\mathrm{NH}_{2}\right.$ primary amino group of CS prior to its chemical modification to a secondary amine). Reported FT-IR peaks and bands confirming the carboxymethylation conversion of CS to N,O-CMCS are consistent with other published studies [37] [55].

\subsection{2. ${ }^{1} \mathrm{H}-\mathrm{NMR}$ Analysis}

${ }^{1} \mathrm{H}$ NMR spectra of CS and N,O-CMCS in $\mathrm{D}_{2} \mathrm{O} / \mathrm{DCl}$ are reported in Figure 3. Despite some similarities retrieved within both spectra, the integration of peaks located at 3.95 and $4.66 \mathrm{ppm}$ can be associated to respectively the $-\mathrm{N}-\mathrm{CH}_{2}$ - and $-\mathrm{O}-\mathrm{CH}_{2}$ - groups assigned to protons on $\mathrm{C} 2$ and $\mathrm{C} 6$ positions of the N,O-CMCS biomaterial. According to our expectations, a greater degree of $\mathrm{N}$-carboxymethylation than O-carboxymethylation is observed. This result demonstrated the higher nucleophilicity of the nitrogen compared to oxygen. As depicted in the ${ }^{1} \mathrm{H}$ NMR spectrum of CS the multiple from 3.40 to $3.90 \mathrm{ppm}$ is corresponding to $\mathrm{H} 3, \mathrm{H} 4, \mathrm{H} 5$, and $\mathrm{H} 6$ protons of the ring. Finally, the broad singlet at $2.90 \mathrm{ppm}$ is owed to the $\mathrm{H} 2$ assigned to both CS and N,O-CMCS spectra [31] [54].

\subsubsection{Zeta Potential Results}

The Zeta potential (ZP) is used to measure the effective electric charge on the membrane's surface; it can provide useful information on possible electrostatic interactions between N,O-CMCS and FLX molecules. Based on the degree of 


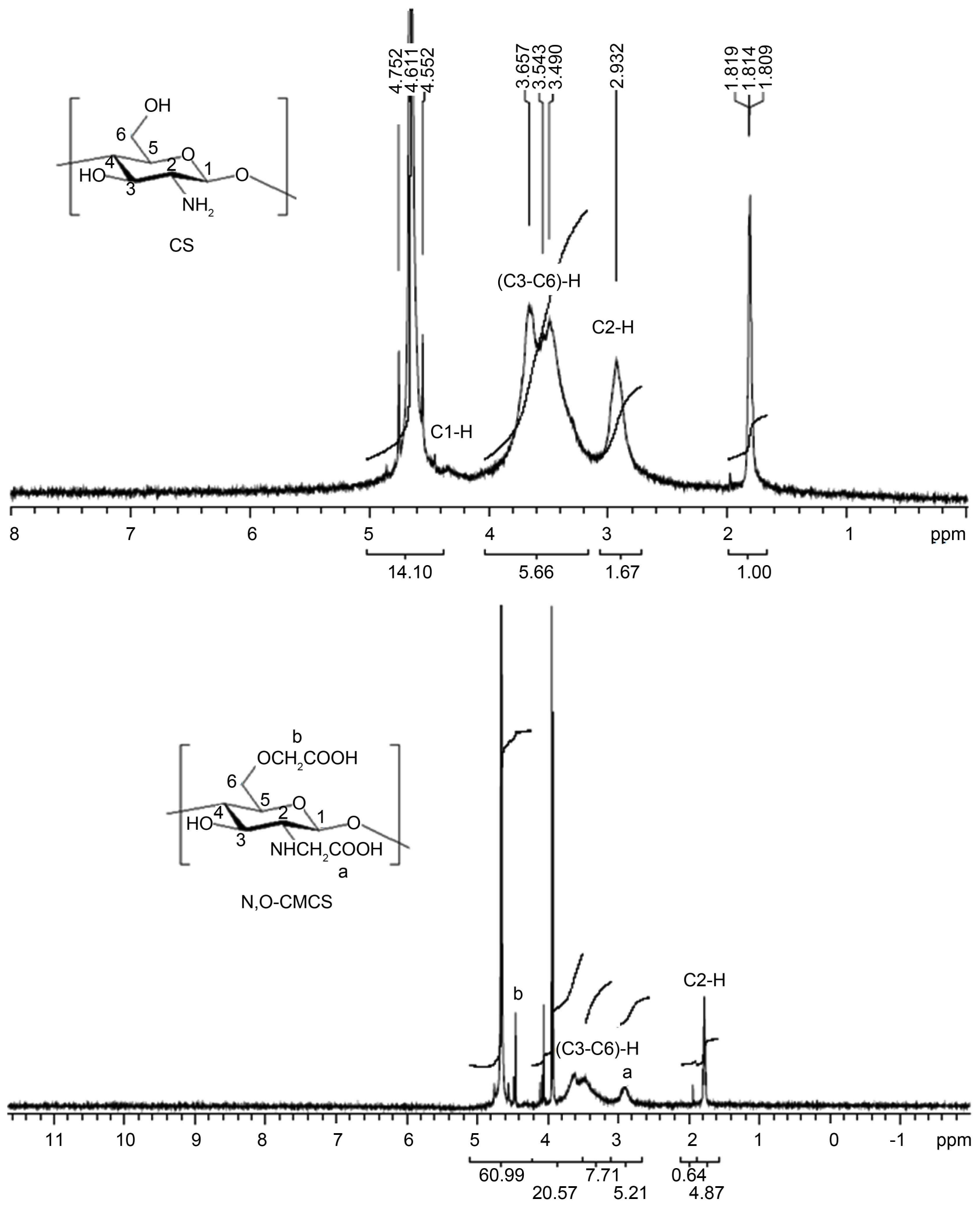

Figure 3. ${ }^{1} \mathrm{H}$ NMR spectra of CS in $\mathrm{D}_{2} \mathrm{O}$ and N,O-CMCS in $\mathrm{D}_{2} \mathrm{O} / \mathrm{DCl}$.

substitution (DS) of the N,O-CMCS calculated using a potentiometric or acid-base titration method, this measure provides information about the ionization 
state of the grafted carboxylic acid moieties on the surface of the modified polymer. Figure 4 shows the $\mathrm{ZP}(\mathrm{mV})$ as a function of $\mathrm{pH}$. As the $\mathrm{pH}$ increased, the $\mathrm{ZP}$ is decreasing to negative values. This indicates that N,O-CMCS becomes highly ionized with negative charges due to larger amount of deprotonated carboxyl groups $\left(-\mathrm{COO}^{-}\right)$. Under alkaline conditions, an electrostatic sorption mechanism is possible and favors the attraction of positive ions toward the negative surface of the modified biomaterial N,O-CMCS. However, at $\mathrm{pH}<4.5$ the $-\mathrm{RNH}_{3}^{+}$ group (from protonated secondary amine) is predominant along with positive $\mathrm{ZP}$ values. Around $\mathrm{pH}$ 4.5, an isoelectric point (pI) is generated by the presence of both charged species (e.g. - $\mathrm{RNH}_{3}^{+} /-\mathrm{RCOO}^{-}$) on the surface. Similar observations are reported in literature [31] [47] [55].

\subsection{Electrospinning Parameters and Stabilization of Nanofiber Mats}

Two of the most critical parameters affecting the electrospinning process are the concentration and the solution's mass ratio N,O-CMCS/PEO, since they play a key role in having defect-free nanofibers. Electrospun N,O-CMCS/PEO nanofiber mats were prepared from aqueous solutions at various $\mathrm{N}, \mathrm{O}-\mathrm{CMCS}$ concentrations and CMCS-PEO mass ratios. PEO was used as a co-polymer agent to facilitate the electrospinning process of CMCS. Electrospun N,O-CMCS/PEO mats were more stable with smaller nanofiber diameters than those obtained with CMCS dissolved in $1 \%$ acetic acid solution. They were also beads-free. In the present study, an optimization was conducted to find out as well the best individual polymers concentrations and right mass ratios of N,O-CMCS/PEO that

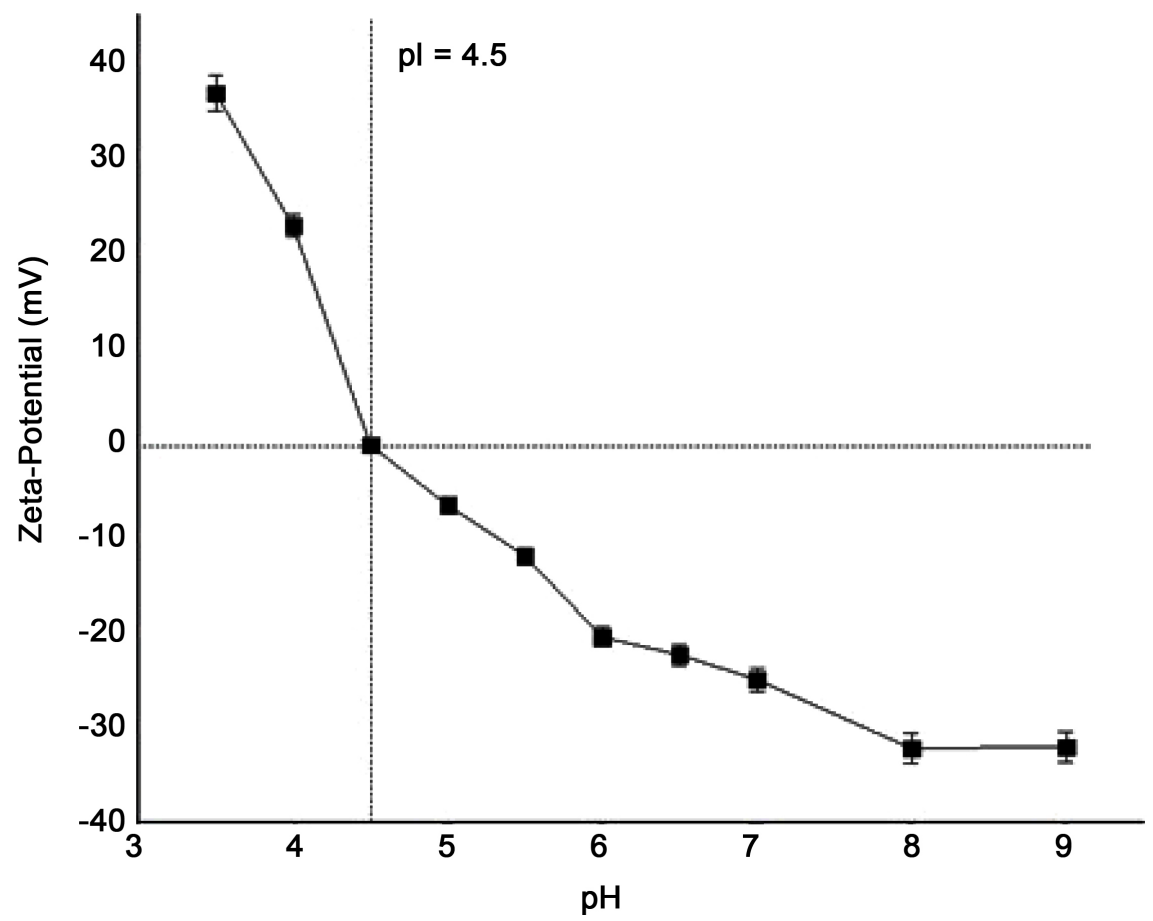

Figure 4. Zeta potential of N,O-CMCS as a function of $\mathrm{pH}$. 
are offering suitable nanofibers web with expected diameters. Results of this optimization analysis are shown in Appendix (Table S1). Electrospinning of aqueous N,O-CMCS/PEO solutions at low concentrations (CMCS/PEO 2.5 wt\%:1.5 wt\%) brought droplets and unstable jet during certain experiments. By contrast, when both CMCS and PEO concentrations were prepared at higher concentrations (CMCS/PEO $8 \mathrm{wt} \%: 8 \mathrm{wt} \%$ ), nanofibers with beads and large diameters were obtained. Therefore, our findings proved that the aqueous mixture composition had an important effect on the morphology and diameter distributions of electrospun nanofibers.

A comparative study of cumulated results from manufactured nanofibers of unmodified CS and modified CS (N,O-CMCS) was also completed. Figure 5 shows SEM images of one CS/PEO electrospun membrane. The material was synthetized using mixed solutions made of CS $2.5 \%$ and PEO 1.5\% (4:1). The CS polymer was dissolved in $90 \%$ acetic acid, and the experimental parameters were as follows: flow rate $0.2 \mathrm{~mL} / \mathrm{h}$, distance tip-collector $7 \mathrm{~cm}$, and voltage $10 \mathrm{kV}$. Electrospinning was carried out at RT and relative humidity ranging between $16 \%-20 \%$. Thus, nanofibers of pure CS $(140 \pm 53 \mathrm{~nm})$ were produced successfully with slight modifications of our previous developed protocol [43].

The optimal aqueous mixture (N,O-CMCS/PEO) was found to be the 4:3 ratio (Table S1). Under such experimental conditions, the best fibers formation was obtained $(176 \pm 40 \mathrm{~nm})$. It is important to mention that the formation of nanofibers is greatly affected by humidity. Indeed, nanofibers were very thin and developed inconsistently at lower humidity levels. However, an electrospraying effect was found when the humidity was higher than $35 \%$. During our optimization study, four N,O-CMCS/PEO mixtures have provided optimal nanofibers formation. Despite the fact we had similar adsorption results with two mass ratios (2.5 wt\%/3 wt\% (4:3); $2.5 \mathrm{wt} \% / 3 \mathrm{wt} \%$ (3:1)), we selected the ratio $4: 3$ mainly because of a more stable jet obtained during winter and summer seasons (fluctuation of humidity observed). In addition, resulting nanofibers using a 4:3 ratio provided better adsorption capacity than other nanofibers synthetized with different N,O-CMCS/PEO mixtures.

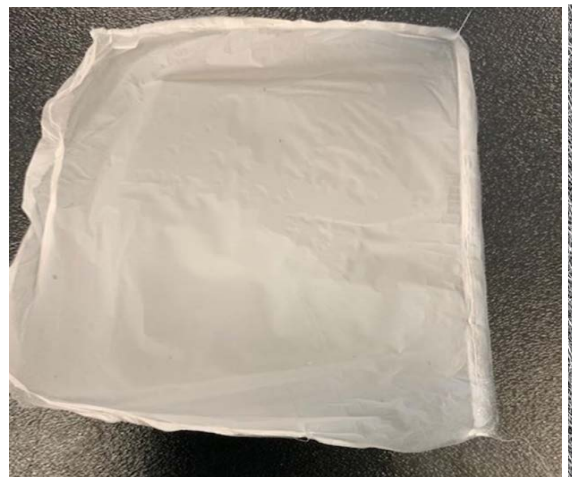

(a)

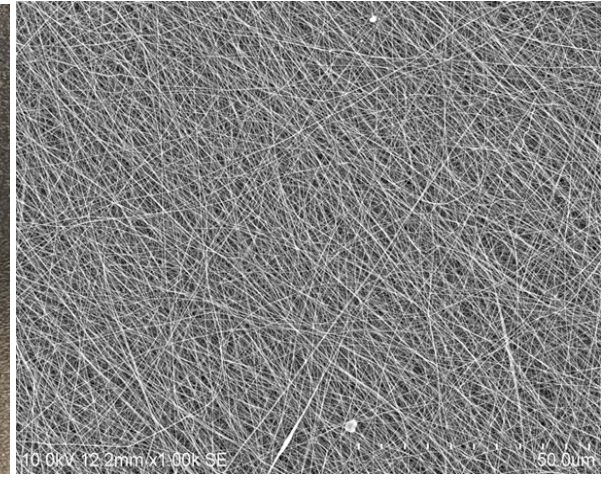

(b)

Figure 5. CS/PEO (4:1) nanofiber mat (a), and respective SEM image (b). 
Optimal heating stabilization conditions of nanofibers were found to be $140^{\circ} \mathrm{C}$ for $30 \mathrm{~min}$. Under these conditions, membranes were stiffened, and fibers were strengthened without any surface modification. In addition, it was observed that the thermal stability was even higher, and the N,O-CMCS membrane was more water-resistant [31]. Many attempts were made to get stable nanofibers in water via different chemical treatments (Figure 6). In all cases, the tested chemical additive was not suitable; they destroyed or altered membranes rather than stabilize them. Therefore, thermal-cross-linking stabilization of membranes at $140^{\circ} \mathrm{C}$ for $30 \mathrm{~min}$ was found the safer and optimal way to stabilize the N,O-CMCS/PEO nanofibers without any surface damage or modification (Figure 7).

\subsection{Adsorption Test and Kinetic Studies}

As shown in Figure 8, FLX was quickly extracted from the solution by N,O-CMCS/PEO nanofibers. The adsorption of FLX reached an equilibrium state after approximately $40 \mathrm{~min}$. The adsorption capacity $(\mathrm{Qt})$ of the targeted drug on the modified nanofibers increased sharply with the extended adsorption time, and then slightly decreased after $120 \mathrm{~min}$. It was interesting to see that almost $75 \%$ of the adsorption capacity was reached in only $10 \mathrm{~min}$. At the end of the adsorption test, close to $85 \%$ of the initial concentration of FLX was removed by the membrane.

To investigate the potential rate-controlling steps involved in the adsorption of FLX onto N,O-CMCS/PEO nanofibers, PFO and PSO kinetic models were used to fit the experimental data. Figure 9 shows the curves for both fitting models. Kinetic parameters are summarized in Table 2 for both models obtained by nonlinear curve fitting of experimental data with MATLAB software to

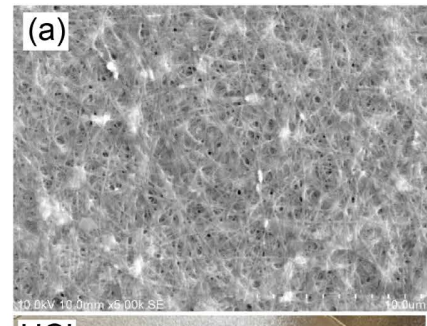

\section{(b)}

$\mathrm{HCl}$
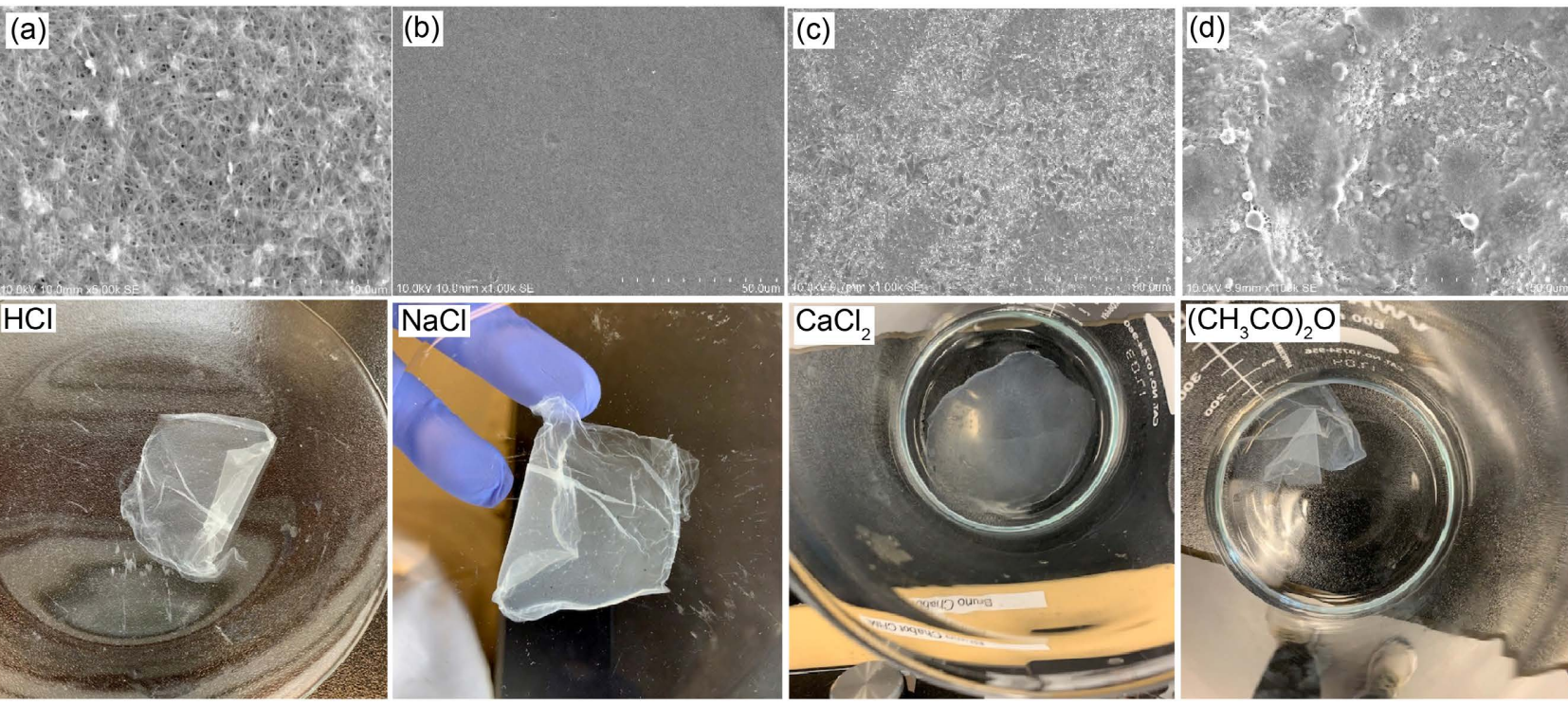

Figure 6. Chemical treatment of stabilization with $\mathrm{HCl}(1 \mathrm{M})$ (a), $\mathrm{NaCl}$ (b), $\mathrm{CaCl}_{2}$ (c), and acetic anhydride (d) for $\mathrm{N}, \mathrm{O}-\mathrm{CMCS} / \mathrm{PEO}$ membrane made of $2.5 \mathrm{wt} \% / 3 \mathrm{wt} \%(4: 3)$. 

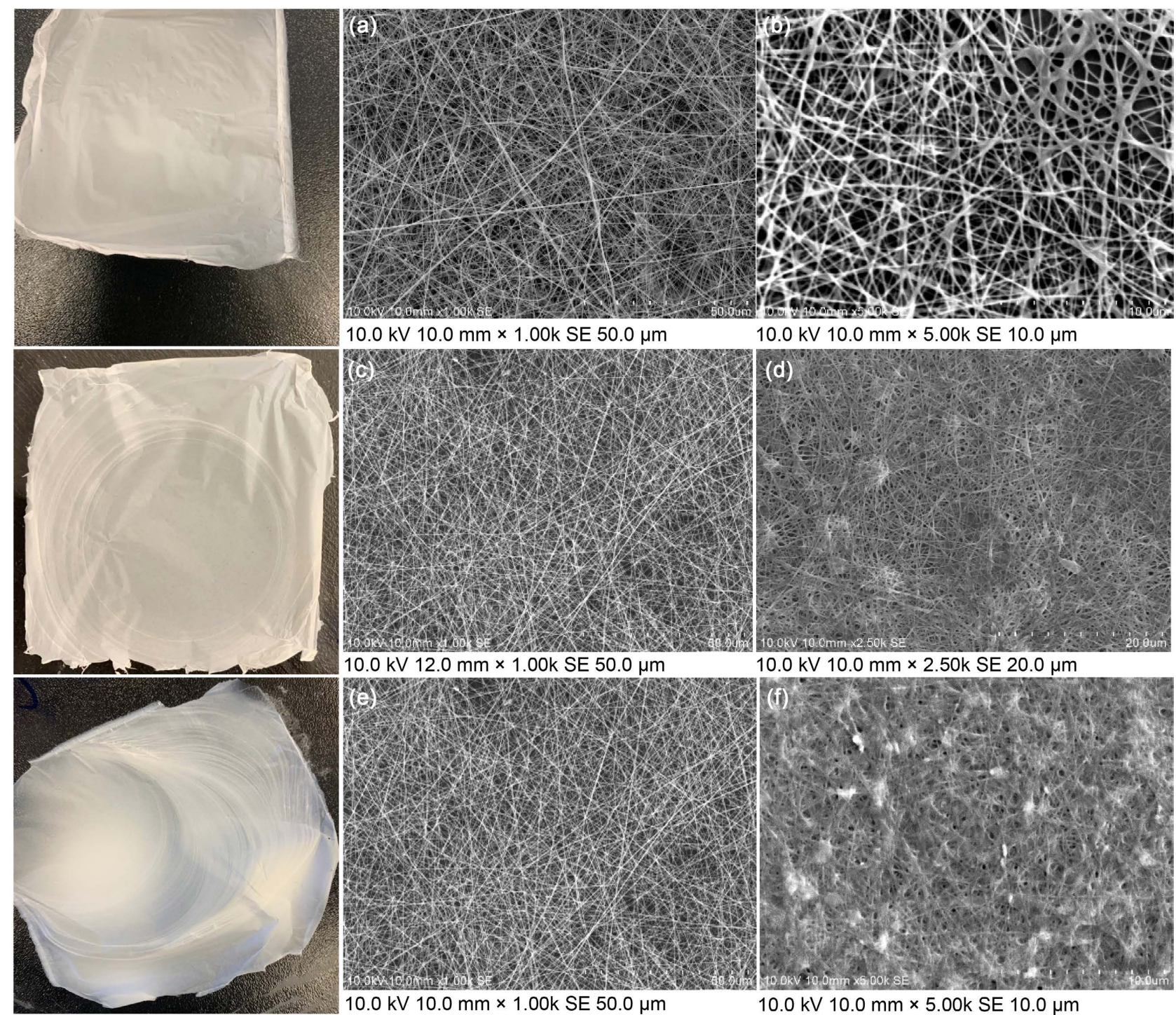

$10.0 \mathrm{kV} 10.0 \mathrm{~mm} \times 1.00 \mathrm{k}$ SE $50.0 \mu \mathrm{m}$

$10.0 \mathrm{kV} 10.0 \mathrm{~mm} \times 5.00 \mathrm{k}$ SE $10.0 \mu \mathrm{m}$
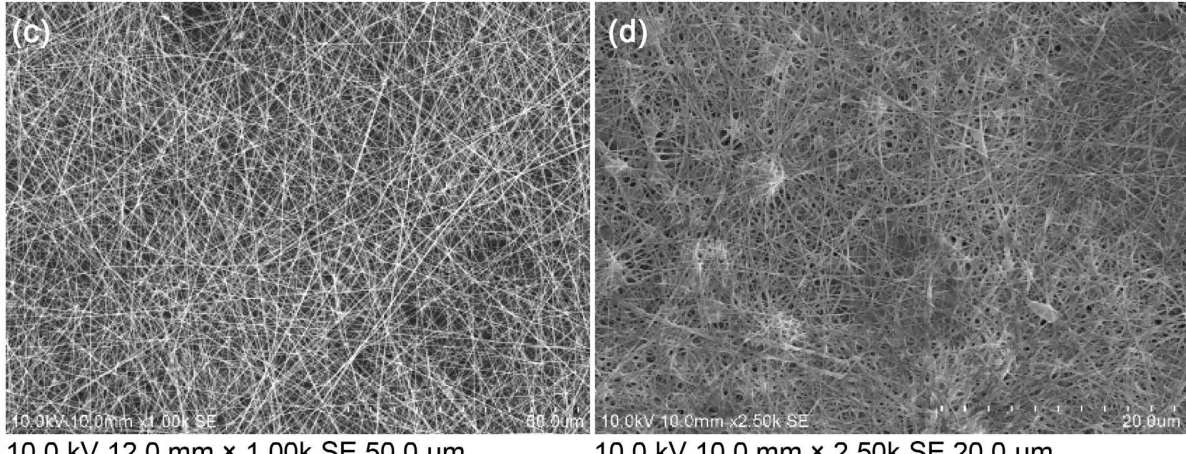

$10.0 \mathrm{kV} 12.0 \mathrm{~mm} \times 1.00 \mathrm{k}$ SE $50.0 \mu \mathrm{m}$

$10.0 \mathrm{kV} 10.0 \mathrm{~mm} \times 2.50 \mathrm{k}$ SE $20.0 \mu \mathrm{m}$

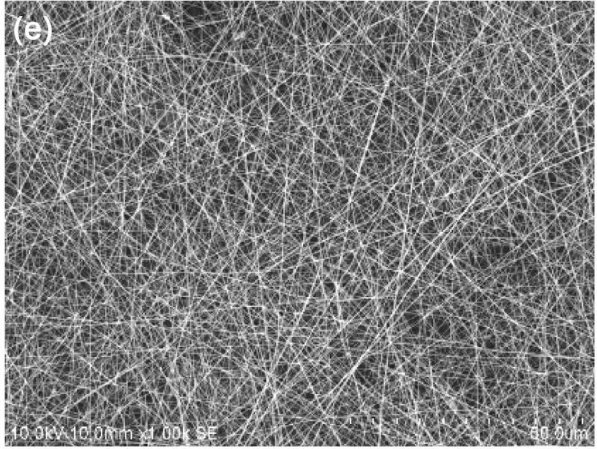

$10.0 \mathrm{kV} 10.0 \mathrm{~mm} \times 1.00 \mathrm{k}$ SE $50.0 \mu \mathrm{m}$

Before

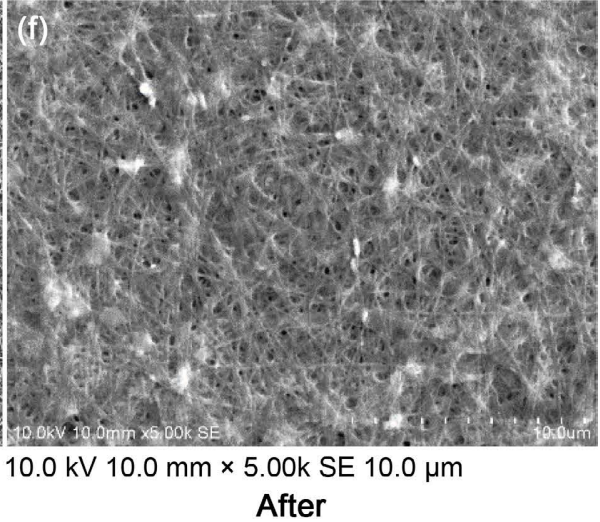

Figure 7. SEM before and after thermal-cross-linking stabilization at $140^{\circ} \mathrm{C}$ for $30 \mathrm{~min}$ for N,O-CMCS/PEO: $2.5 \mathrm{wt} \% / 3 \mathrm{wt} \%$ (3:1) ((a), (b)); (4:3) ((c), (d)); 8 wt\%/1.5 wt\% (3:1) ((e), (f)).

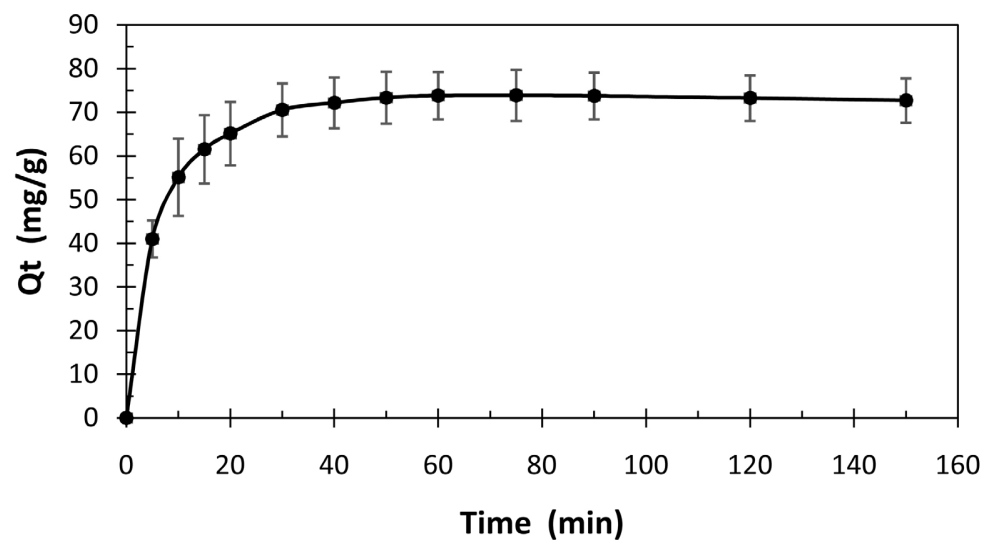

Figure 8. Adsorption capacity of FLX by N,O-CMCS/PEO $2.5 \mathrm{wt} \% / 3 \mathrm{wt} \%$ $(4: 3)$ at $(\mathrm{pH}=8)$ electrospun nanofibers. 


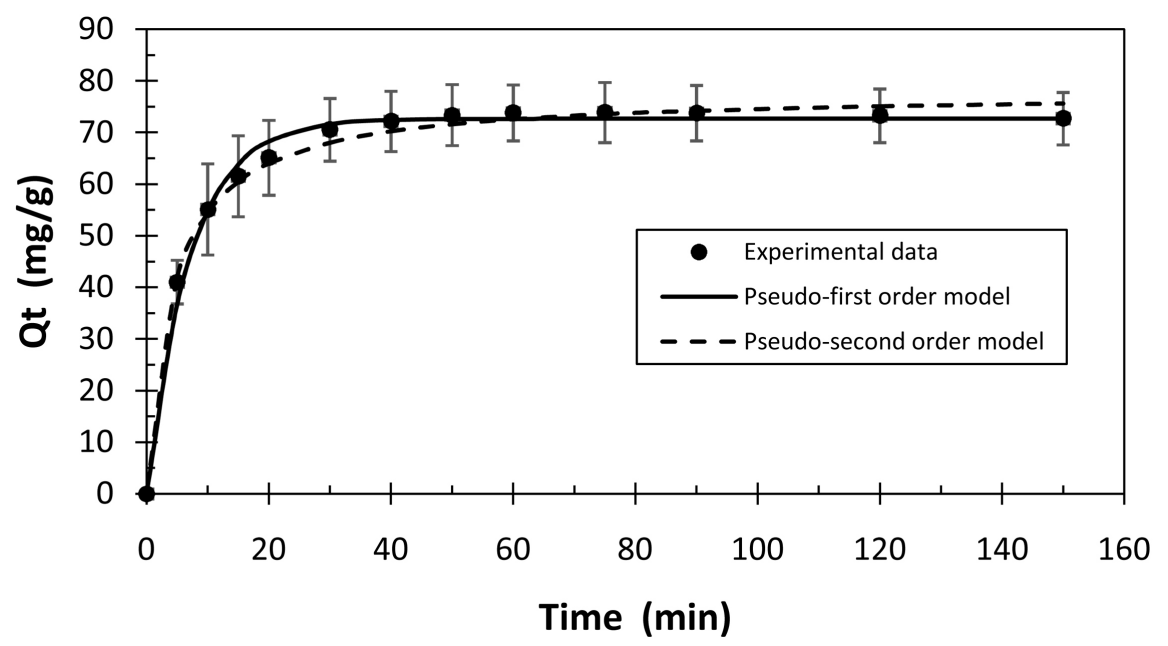

Figure 9. Kinetic models for adsorption of fluoxetine onto the N,O-CMCS/PEO 2.5 wt $\% / 3$ wt $\%$ (4:3) nanofibers.

Table 2. Kinetic models parameters for the adsorption of FLX on N,O-CMCS/PEO 2.5 wt\%/3 wt\% (4:3) nanofibers membrane: Initial concentration $50 \mathrm{mg} / \mathrm{L}, \mathrm{pH} 8.0$, adsorbent $25 \mathrm{mg}, t=150 \mathrm{~min}$ at $25^{\circ} \mathrm{C}$.

\begin{tabular}{ccccccc}
\hline & \multicolumn{3}{c}{ Pseudo first order model } & \multicolumn{3}{c}{ Pseudo second order model } \\
\cline { 2 - 7 } Experimental & $\begin{array}{c}k_{1} \\
\left(\mathrm{~min}^{-1}\right)\end{array}$ & $\begin{array}{c}Q_{e} \\
(\mathrm{mg} / \mathrm{g})\end{array}$ & $R^{2}$ & $\begin{array}{c}k_{2} \\
\left(\mathrm{~min}^{-1}\right)\end{array}$ & $\begin{array}{c}Q_{e} \\
(\mathrm{mg} / \mathrm{g})\end{array}$ & $R^{2}$ \\
\hline $\mathrm{pH} 4.4$ & 0.115 & 37.26 & 0.9987 & 0.0249 & 42.28 & 0.9863 \\
$\mathrm{pH} 8.0$ & 0.1434 & 72.63 & 0.9925 & 0.0031 & 77.72 & 0.9949 \\
\hline
\end{tabular}

reduce statistical discrimination bias [56].

The correlation coefficients $\left(R^{2}\right)$ of the pseudo-first-order and pseudo-second-order curves at $\mathrm{pH} 4.4$ were respectively $0.9987,0.9863$. However, at $\mathrm{pH}$ 8.0, calculated values of $R^{2}$ were 0.9925 and 0.9949 . The higher rate of adsorption $\left(Q_{t}=79.7 \pm 7.9 \mathrm{mg} / \mathrm{g}\right)$ of FLX on N,O-CMCS nanofibers was obtained at $\mathrm{pH}$ 8.0. Based on $\mathrm{R}^{2}$, kinetics curves at $\mathrm{pH} 8.0$ followed a PSO rather than a PFO model. Therefore, a PSO kinetics might imply that the interaction between adsorbate and nanofibers is proceeding via chemisorption (e.g. electrostatic and ionic bonds). This type of interaction is in agreement with the experimental conditions carried out under a $\mathrm{pH}$ of 8.0. Precisely, N,O-CMCS nanofibers are presenting a negative ionized form $(\mathrm{pKa} \mathrm{COOH}=4.5)$, while FLX recognized as a weak base is protonated with a positive charge (pKa: 9.8). Interestingly, when the $\mathrm{pH}$ of the solution was 4.4, a PFO kinetic model was obtained revealing a process that could be much more governed by physical interactions (e.g. van der Waals and hydrogen bonds) at the surface of the modified biopolymer. The non-ionized form of the modified biopolymer is dominant along with its hydrophobic character (Figure 4). Accordingly, the removal yield of FLX under acidic condition is falling to $54 \%$.

During batch adsorption tests, $\mathrm{pH}$ values ranged from 2 to 10 . The maximum 
Table 3. Comparison of different existing adsorbents used for FLX removal.

\begin{tabular}{|c|c|c|c|}
\hline Adsorbents & $\begin{array}{c}\text { Adsorption } \\
\text { capacity } \\
(\mathrm{mg} / \mathrm{g})\end{array}$ & $\mathrm{pH}$ & References \\
\hline $\mathrm{N}, \mathrm{O}-\mathrm{CMCS} / \mathrm{PEO}$ nanofibers & 79.7 & 8 & - \\
\hline Hydrochar, activated carbons & 44.1 & 7 & [57] \\
\hline Biochar, rice branpyrolysis & 67.6 & 7 & {$[58]$} \\
\hline Biochar, Eucalyptus pyrolysis & 6.4 & 7 & [59] \\
\hline Granular activated carbon and two synthetic zeolites (GAC) & 234 & 9 & \\
\hline Synthetic zeolites (zeolite $13 \times$ ) & 32.1 & 7 & {$[60]$} \\
\hline Synthetic zeolites (zeolite 4A) & 21.9 & 9 & \\
\hline$\beta$-Cyclodextrin carboxymethyl cellulose $(\beta$-CD-CMC) polymer & 5.1 & 7 & [61] \\
\hline Lignin/PVA nanofibers & 78.2 & 7 & [44] \\
\hline Paper mill sludge-based activated carbon with $\mathrm{ZnCl}_{2}$ & 28.4 & 7 & {$[62]$} \\
\hline
\end{tabular}

adsorption capacities of the adsorbent in acidic solution $(\mathrm{pH}=4.4)$ were around $53.60 \mathrm{mg} / \mathrm{g}$, in comparison to $79.7 \mathrm{mg} / \mathrm{g}$ when the $\mathrm{pH}$ was adjusted to a value of 8.0. The $\mathrm{pH}$ change of the medium had a direct impact on the rate of adsorption. Despite the good results obtained in this study, additional tests (e.g. temperature changes, weight of adsorbent, determination of isotherms and thermodynamics) are required: 1) to better understand the sorption mechanisms at the surface of the N,O-CMCS nanofibers, and 2) to improve its efficiency in terms of absorption rate. Finally, other tests will be carried out on the reusability of the new adsorbent with consecutive adsorption/desorption cycles.

Serious challenges to meet increasing demands for clean water resources have been driving advances in technology including the use of low cost, abundant, and "green" adsorbent biomaterials. In the last decade, some articles were published on the removal of FLX in water by adsorption using different adsorbents manufactured from materials. A list of adsorbents along with their respective adsorption capacity is provided in Table 3. A comparison of the different adsorption capacities demonstrates the promising efficiency of N,O-CMCS/PEO nanofibers. Indeed, the developed nanometric membranes are offering large specific surface area and versatility in the choice of retention sought. Depending on the type of molecules to be removed, a higher level of specificity can be achieved by simply adjusting the $\mathrm{pH}$ of the medium. This clearly open-up new interesting perspectives in terms of adsorption strategies (e.g. successive extractions of contaminants having different physicochemical properties).

\section{Conclusion}

The study presented an optimized methodology for the synthesis of N,O-CMCS/PEO electrospun nanofibers $(176 \pm 40 \mathrm{~nm})$ used as adsorbent. The developed membranes exhibited an excellent ability for the removal of FLX from 
water at $\mathrm{pH} 8.0$ (adsorption capacity up to $79.7 \pm 7.9 \mathrm{mg} / \mathrm{g}$ ). Kinetics tests performed on N,O-CMCS/PEO nanofibers under optimized conditions gave a better correlation with the PSO model. Data analysis is suggesting a possible chemisorption mechanism between FLX and the N,O-CMCS/PEO nanofibers. However, further tests (e.g. isotherms, thermodynamic) will be attempted in the near future to better understand the adsorption mechanism at the surface of the modified biomaterial. From promising results obtained so far during our experiments, and a comparison made with other existing sorbents, N,O-CMCS/PEO nanofibers are believed to be efficient and suitable to remove pharmaceutical residues such FLX in water.

\section{Acknowledgements}

The authors gratefully acknowledge Professor Benoit Daoust from Université du Québec à Trois-Rivières for his useful advices in organic synthesis. Alexandre Camiré, Jocelyn Bouchard and Jean-Philippe Marineau are also acknowledged for their technical assistance, as well as Agnès Lejeune for SEM images and Maribel Díaz for the Matlab training. This study was supported by the Natural Sciences and Engineering Research Council (NSERC) of Canada (Discovery Grant), the Libyan-North American Scholarship Program (LNASP), the Canadian Bureau for International Education (CBIE), the strategic research group EcotoQ, and the Fonds de recherche du Québec-Nature et Technologie (FRQNT).

\section{Conflicts of Interest}

The authors declare no conflicts of interest regarding the publication of this paper.

\section{References}

[1] Rhazi, M., Desbrières, J., Tolaimate, A., Rinaudo, M., Vottero, P., Alagui, A. and El Meray, M. (2002) Influence of the Nature of the Metal Ions on the Complexation with Chitosan: Application to the Treatment of Liquid Waste. European Polymer Journal, 38, 1523-1530. https://doi.org/10.1016/S0014-3057(02)00026-5

[2] Lockwood, S., Saïdi, N. and Morgan, V.A. (2016) Options for a Strategic Approach to Pharmaceuticals in the Environment Task 1 Report-Revised Version. Deloitte, INERIS (French National Institute for Industrial Environment and Risks), Klaus Kümmerer, LSE (The London School of Economics and Political Science), Milieu Ltd., European Commission-DG ENV, Tokyo, Japan.. Deloitte SA. Member of Deloitte Touche Tohmatsu Limited, Tokyo, Japan.

[3] Patel, M., Kumar, R., Kishor, K., Mlsna, T., Pittman, C.U. and Mohan, D. (2019) Pharmaceuticals of Emerging Concern in Aquatic Systems: Chemistry, Occurrence, Effects, and Removal Methods. Chemical Reviews, 119, 3510-3673. https://doi.org/10.1021/acs.chemrev.8b00299

[4] Liu, J.L. and Wong, M.H. (2013) Pharmaceuticals and Personal Care Products (PPCPs): A Review on Environmental Contamination in China. Environment International, 59, 208-224. https://doi.org/10.1016/j.envint.2013.06.012 
[5] Carballa, M., Omil, F., Lem, M.J., Llompart, M., García-Jares, C., Rodríguez, I., Gómez, M. and Ternes, T. (2004) Behavior of Pharmaceuticals, Cosmetics and Hormones in a Sewage Treatment Plant. Water Research, 38, 2918-2926. https://doi.org/10.1016/j.watres.2004.03.029

[6] Kasprzyk-Hordern, B., Dinsdale, R.M. and Guwy, A.J. (2009) The Removal of Pharmaceuticals, Personal Care Products, Endocrine Disruptors and Illicit Drugs during Wastewater Treatment and Its Impact on the Quality of Receiving Waters. Water Research, 43, 363-380. https://doi.org/10.1016/j.watres.2008.10.047

[7] Ericson, J.F., Laenge, R. and Sullivan, D.E. (2002) Comment on "Pharmaceuticals, Hormones, and Other Organic Wastewater Contaminants in U.S. Streams, 1999-2000: A National Reconnaissance”. Environmental Science \& Technology, 36, 4005-4006. https://doi.org/10.1021/es0200903

[8] Lajeunesse, A., Gagnon, C., Gagné, F., Louis, S., Čejka, P. and Sauvé, S. (2011) Distribution of Antidepressants and Their Metabolites in Brook Trout Exposed to Municipal Wastewaters before and after Ozone Treatment-Evidence of Biological Effects. Chemosphere, 83, 564-571. https://doi.org/10.1016/j.chemosphere.2010.12.026

[9] Lishman, L., Smyth, S.A., Sarafin, K., Kleywegt, S., Toito, J., Peart, T., Lee, B., Servos, M., Beland, M. and Seto, P. (2006) Occurrence and Reductions of Pharmaceuticals and Personal Care Products and Estrogens by Municipal Wastewater Treatment Plants in Ontario, Canada. Science of the Total Environment, 367, 544-558. https://doi.org/10.1016/j.scitotenv.2006.03.021

[10] Kyzas, G.Z., Kostoglou, M., Lazaridis, N.K., Lambropoulou, D.A. and Bikiaris, D.N. (2013) Environmental Friendly Technology for the Removal of Pharmaceutical Contaminants from Wastewaters Using Modified Chitosan Adsorbents. Chemical Engineering Journal, 222, 248-258. https://doi.org/10.1016/j.cej.2013.02.048

[11] Lajeunesse, A., Smyth, S.A., Barclay, K., Sauvé, S. and Gagnon, C. (2012) Distribution of Antidepressant Residues in Wastewater and Biosolids Following Different Treatment Processes by Municipal Wastewater Treatment Plants in Canada. Water Water Research, 46, 5600-5612. https://doi.org/10.1016/j.watres.2012.07.042

[12] Heberer, T. (2002) Occurrence, Fate, and Removal of Pharmaceutical Residues in the Aquatic Environment: A Review of Recent Research Data. Toxicology Letters, 131, 5-17. https://doi.org/10.1016/S0378-4274(02)00041-3

[13] Wang, J. and Wang, S. (2016) Removal of Pharmaceuticals and Personal Care Products (PPCPs) from Wastewater: A Review. Journal of Environmental Management, 182, 620-640. https://doi.org/10.1016/j.jenvman.2016.07.049

[14] Zhou, H. and Smith, D.W. (2001) Advanced Technologies in Water and Wastewater Treatment. Canadian Journal of Civil Engineering, 28, 49-66. https://doi.org/10.1139/100-091

[15] Upadhyay, U., Sreedhar, I., Singh, S.A., Patel, C.M. and Anitha, K.L. (2021) Recent Advances in Heavy Metal Removal by Chitosan Based Adsorbents. Carbohydrate Polymers, 251, Article ID: 117000. https://doi.org/10.1016/j.carbpol.2020.117000

[16] Abebe, B., Murthy, H.C.A. and Amare, E. (2018) Summary on Adsorption and Photocatalysis for Pollutant Remediation. Journal of Encapsulation and Adsorption Sciences, 8, 225-255. https://doi.org/10.4236/jeas.2018.84012

[17] Fukahori, S., Fujiwara, T., Ito, R. and Funamizu, N. (2011) PH-Dependent Adsorption of Sulfa Drugs on High Silica Zeolite: Modeling and Kinetic Study. Desalination, 275, 237-242. https://doi.org/10.1016/j.desal.2011.03.006

[18] Bui, T.X. and Choi, H. (2009) Adsorptive Removal of Selected Pharmaceuticals by 
Mesoporous Silica SBA-15. Journal of Hazardous Materials, 168, 602-608. https://doi.org/10.1016/j.jhazmat.2009.02.072

[19] Baccar, R., Sarrà, M., Bouzid, J., Feki, M. and Blánquez, P. (2012) Removal of Pharmaceutical Compounds by Activated Carbon Prepared from Agricultural By-Product. Chemical Engineering Journal, 211-212, 310-317. https://doi.org/10.1016/j.cej.2012.09.099

[20] Chen, X.G. and Park, H.J. (2003) Chemical Characteristics of O-Carboxymethyl Chitosans Related to the Preparation Conditions. Carbohydrate Polymers, 53, 355-359. https://doi.org/10.1016/S0144-8617(03)00051-1

[21] Kweon, D.K., Song, S.B. and Park, Y.Y. (2003) Preparation of Water-Soluble Chitosan/Heparin Complex and Its Application as Wound Healing Accelerator. Biomaterials, 24, 1595-1601. https://doi.org/10.1016/S0142-9612(02)00566-5

[22] Jayakumar, R., Nwe, N., Tokura, S. and Tamura, H. (2007) Sulfated Chitin and Chitosan as Novel Biomaterials. International Journal of Biological Macromolecules, 40, 175-181. https://doi.org/10.1016/j.ijbiomac.2006.06.021

[23] Jayakumar, R., Prabaharan, M., Reis, R.L. and Mano, J.F. (2005) Graft Copolymerized Chitosan-Present Status and Applications. Carbohydrate Polymers, 62, 142-158. https://doi.org/10.1016/j.carbpol.2005.07.017

[24] Vidal, R.R.L. and Moraes, J.S. (2019) Removal of Organic Pollutants from Wastewater Using Chitosan. International Journal of Environmental Science and Technology, 16, 1741-1754. https://doi.org/10.1007/s13762-018-2061-8

[25] Singh, N., Kamath, V., Narasimhamurthy, K. and Rajini, P.S. (2008) Protective Effect of Potato Peel Extract against Carbon Tetrachloride-Induced Liver Injury in Rats. Environmental Toxicology and Pharmacology, 26, 241-246. https://doi.org/10.1016/j.etap.2008.05.006

[26] Jayakumar, R., Nair, S.V., Furuike, T. and Tamura, H. (2010) Perspectives of Chitin and Chitosan Nanofibrous Scaffolds In: Eberli, D., Ed., Tissue Engineering, IntechOpen, London, 1-22. https://doi.org/10.5772/8593

[27] Boricha, A.G. and Murthy, Z.V.P. (2010) Preparation of N,O-Carboxymethyl Chitosan/Cellulose Acetate Blend Nanofiltration Membrane and Testing Its Performance in Treating Industrial Wastewater. Chemical Engineering Journal, 157, 393-400. https://doi.org/10.1016/j.cej.2009.11.025

[28] Shoukry, A.A. and Hosny, W.M. (2012) Coordination Properties of N,O-Carboxymethyl Chitosan (NOCC). Synthesis and Equilibrium Studies of Some Metal Ion Complexes. Ternary Complexes Involving $\mathrm{Cu}(\mathrm{II})$ with (NOCC) and Some Biorelevant Ligand. Open Chemistry, 10, 59-70. https://doi.org/10.2478/s11532-011-0116-5

[29] Vaghani, S.S., Patel, M.M., Satish, C.S., Patel, K.M. and Jivani, N.P. (2012) Synthesis and Characterization of Carboxymethyl Chitosan Hydrogel: Application as Site Specific Delivery for Lercanidipine Hydrochloride. Bulletin of Materials Science, 35, 1133-1142. https://doi.org/10.1007/s12034-012-0413-4

[30] Chen, S.C., Wu, Y.C., Mi, F.L., Lin, Y.H., Yu, L.C. and Sung, H.W. (2004) A Novel pH-Sensitive Hydrogel Composed of N,O-Carboxymethyl Chitosan and Alginate Cross-Linked by Genipin for Protein Drug Delivery. Journal of Controlled Release, 96, 285-300. https://doi.org/10.1016/j.jconrel.2004.02.002

[31] Du, J. and Lo Hsieh, Y. (2008) Nanofibrous Membranes from Aqueous Electrospinning of Carboxymethyl Chitosan. Nanotechnology, 19, Article ID: 125707. https://doi.org/10.1088/0957-4484/19/12/125707

[32] Kusuma, H.S., Al-Sa'bani, A.F. and Darmokoesoemo, H. (2015) N,O-Carboxymethyl Chitosan: An Innovation in New Natural Preservative from Shrimp Shell Waste with a 
Nutritional Value and Health Orientation. Procedia Food Science, 3, 35-51. https://doi.org/10.1016/j.profoo.2015.01.004

[33] Kurniasih, M., Purwati, P., Hermawan, D. and Zaki, M. (2014) Optimum Conditions for the Synthesis of High Solubility Carboxymethyl Chitosan. Malaysian Journal of Fundamental and Applied Sciences, 10, 189-194. https://doi.org/10.11113/mjfas.v10n4.277

[34] El-Sherbiny, I.M. (2009) Synthesis, Characterization and Metal Uptake Capacity of a New Carboxymethyl Chitosan Derivative. European Polymer Journal, 45, 199-210. https://doi.org/10.1016/j.eurpolymj.2008.10.042

[35] Bukzem, A.L., Signini, R., dos Santos, D.M., Lião, L.M. and Ascheri, D.P.R. (2016) Optimization of Carboxymethyl Chitosan Synthesis Using Response Surface Methodology and Desirability Function. International Journal of Biological Macromolecules, 85, 615-624. https://doi.org/10.1016/j.ijbiomac.2016.01.017

[36] Ge, H.C. and Luo, D.K. (2005) Preparation of Carboxymethyl Chitosan in Aqueous Solution under Microwave Irradiation. Carbohydrate Research, 340, 1351-1356. https://doi.org/10.1016/j.carres.2005.02.025

[37] Bidgoli, H., Zamani, A. and Taherzadeh, M.J. (2010) Effect of Carboxymethylation Conditions on the Water-Binding Capacity of Chitosan-Based Superabsorbents. Carbohydrate Research, 345, 2683-2689. https://doi.org/10.1016/j.carres.2010.09.024

[38] Jayakumar, R.,Prabaharanand, M., Nair, S.V., Tokura, S. and Selvamurugan N. (2010) Novel Carboxymethyl Derivatives of Chitin and Chitosan Materials and Their Biomedical Applications. Progress in Materials Science, 55,675-709. https://doi.org/10.1016/j.pmatsci.2010.03.001

[39] Riza,F., Ftikos, C., Tietz, F. and Fischer, W. (2001) Preparation and Characteriza-

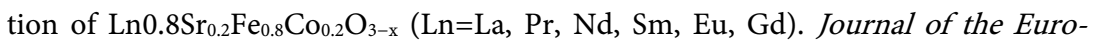
pean Ceramic Society, 21, 1769-1773. https://doi.org/10.1016/S0955-2219(01)00112-1

[40] Lin, C.C. and Lin, C.W. (2009) Preparation of N,O-Carboxymethyl Chitosan Nanoparticles as an Insulin Carrier. Drug Delivery, 16, 458-464. https://doi.org/10.3109/10717540903353090

[41] Ghazal, H.A., El-Masry, A.A.M. and Mosaad, R.M. (2021) Multifunction Finishing of Cellulose Based Fabrics via 3-Chloro-2-hydroxypropyl Trimethyl Ammonium Chloride (Quat-188) and Silver Nanoparticles (AgNPs) to Improve Its Dyeability and Antibacterial. Biointerface Research in Applied Chemistry, 11, 11666-11678. https://doi.org/10.33263/BRIAC114.1166611678

[42] Sakib, M.N., Mallik, A.K. and Rahman, M.M. (2021) Update on Chitosan-Based Electrospun Nanofibers for Wastewater Treatment. Carbohydrate Polymer Technologies and Applications, 2, Article ID: 100064.

https://doi.org/10.1016/j.carpta.2021.100064

[43] Paradis-Tanguay, L., Camiré, A., Renaud, M., Chabot, B. and Lajeunesse, A. (2019) Sorption Capacities of Chitosan/Polyethylene Oxide (PEO) Electrospun Nanofibers Used to Remove Ibuprofen in Water. Journal of Polymer Engineering, 39, 207-215. https://doi.org/10.1515/polyeng-2018-0224

[44] Camiré, A., Espinasse, J., Chabot, B. and Lajeunesse, A. (2020) Development of Electrospun Lignin Nanofibers for the Adsorption of Pharmaceutical Contaminants in Wastewater. Environmental Science and Pollution Research, 27, 3560-3573. https://doi.org/10.1007/s11356-018-3333-Z

[45] Sun, S. and Wang, A. (2006) Adsorption Kinetics of $\mathrm{Cu}$ (II) Ions Using 
N,O-Carboxymethyl-Chitosan. Journal of Hazardous Materials, 131, 103-111. https://doi.org/10.1016/j.jhazmat.2005.09.012

[46] Lu, S., Song, X., Cao, D., Chen, Y. and Yao, K. (2004) Preparation of Water-Soluble Chitosan. Journal of Applied Polymer Science, 91, 3497-3503. https://doi.org/10.1002/app.13537

[47] Kalliola, S., Repo, E., Srivastava, V., Zhao, F., Heiskanen, J.P., Sirviö, J.A., Liimatainen, H. and Sillanpää, M. (2018) Carboxymethyl Chitosan and Its Hydrophobically Modified Derivative as pH-Switchable Emulsifiers. Langmuir, 34, 2800-2806. https://doi.org/10.1021/acs.langmuir.7b03959

[48] Largitte, L. and Pasquier, R. (2016) A Review of the Kinetics Adsorption Models and Their Application to the Adsorption of Lead by an Activated Carbon. Chemical Engineering Research and Design, 109, 495-504.

https://doi.org/10.1016/j.cherd.2016.02.006

[49] Ahmed,M.A., Li M., Sanjrani, M.A., Abdelaal,S.A.A., Norville, B., Zhan, Z.W. and $\mathrm{Du}, \mathrm{N}$. (2020) Mechanisms and Models of Adsorption: $\mathrm{TiO}_{2}-S$ Supported Biochar for Removal of 3,4-Dimethylaniline. ACS Omega, 5, 13630-13640. https://doi.org/10.1021/acsomega.0c00619

[50] Del Prado-Audelo, M.L. (2021) A New Formulation of Cinnamon Oil and Chitosan Depolymerized against Opportunistic Microorganisms during Wound Healing. Farmacia, 69, 509-514. https://doi.org/10.31925/farmacia.2021.3.13

[51] Abreu, F.R. and Campana-Filho, S.P. (2009) Characteristics and Properties of Carboxymethylchitosan. Carbohydrate Polymers, 75, 214-221.

https://doi.org/10.1016/j.carbpol.2008.06.009

[52] Li, Z., Zhuang, X.P., Liu, X.F., Guan, Y.L. and De Yao, K. (2002) Study on Antibacterial $O$-Carboxymethylated Chitosan/Cellulose Blendfilm from $\mathrm{LiCl} / N$, $N$-Dimethylacetamide Solution. Polymer, 43, 1541-1547. https://doi.org/10.1016/S0032-3861(01)00699-1

[53] Siahaan, P., Mentari, N.C., Wiedyanto, U.O., Hudiyanti, D., Hildayani, S.Z. and Laksitorini, M.D. (2017) The Optimum Conditions of Carboxymethyl Chitosan Synthesis on Drug Delivery Application and Its Release of Kinetics Study. Indonesian Journal of Chemistry, 17, 291-300. https://doi.org/10.22146/ijc.24252

[54] de Abreu, F.R. and Campana-Filho, S.P. (2005) Preparation and Characterization of Carboxymethylchitosan. Polímeros. Ciência e Tecnologia, 15, 79-83.

https://doi.org/10.1590/S0104-14282005000200004

[55] Kalliola, S., Repo, E., Srivastava, V., Heiskanen, J.P., Sirviö, J.A., Liimatainen, H. and Sillanpää, M. (2017) The pH Sensitive Properties of Carboxymethyl Chitosan Nanoparticles Cross-Linked with Calcium Ions. Colloids and Surfaces B: Biointerfaces, 153, 229-236. https://doi.org/10.1016/j.colsurfb.2017.02.025

[56] Quiñones, J.P., Peniche, H. and Peniche, C. (2018) Chitosan Based Self-Assembled Nanoparticles in Drug Delivery. Polymers, 10, Article No. 235.

https://doi.org/10.3390/polym10030235

[57] Román, S., Valente Nabais, J.M., Ledesma, B., Laginhas, C. and Titiric, M.M. (2020) Surface Interactions during the Removal of Emerging Contaminants by Hydrochar-Based Adsorbent. Molecules, 25, Article No. 2264. https://doi.org/10.3390/molecules25092264

[58] Escudero-Curiel, S., Acevedo-García, V., Sanrománand M.A. and Pazos M. (2021) Eco-Approach for Pharmaceutical Removal: Thermochemical Waste Valorisation, biochar Adsorption and Electro-Assisted Regeneration. Electrochemica Acta, 389, Article ID: 138694. https://doi.org/10.1016/j.electacta.2021.138694 
[59] Fernandes, M.J., Moreira, M.M., Paíga, P., Dias, D., Bernardo, M., Carvalho, M., Lapa, N., Fonseca, I., Morais, S., Figueiredo, S. and Delerue-Matos, C. (2019) Evaluation of the Adsorption Potential of Biochars Prepared from Forest Andagri-Food Wastes for the Removal of Fluoxetine. Bioresource Technology, 292, Article ID: 121973. https://doi.org/10.1016/j.biortech.2019.121973

[60] Silva, B., Martins, M., Rosca, M., Rocha, V., Lago, A., Neves, I.C. and Tavares, T. (2020) Waste-Based Biosorbents as Cost-Effective Alternatives to Commercial Adsorbents for the Retention of Fluoxetine from Water. Separation and Purification Technology, 235, Article ID: 116139. https://doi.org/10.1016/j.seppur.2019.116139

[61] Bonenfant, D., Mimeault, M., Niquette, P. and Hausler, R. (2012) Adsorption Study of a Commonly Used Antidepressant Drug, Fluoxetine Hydrochloride, onto a Crosslinked $\beta$-Cyclodextrin-Carboxymethylcellulose Polymer. Water Science \& Technology, 66, 224-230. https://doi.org/10.2166/wst.2012.112

[62] Jaria, G., Calisto, V., Gil, M.V., Otero, M. and Esteves V.I. (2015) Removal of Fluoxetine from Water by Adsorbent Materials Produced from Paper Mill Sludge. Journal of Colloid and Interface Science, 448, 32-40.

https://doi.org/10.1016/j.jcis.2015.02.002 


\section{Appendix}

Table S1. Effect of CMCS/PEO ratio on electrospinning using different CMCS and PEO solution concentrations.

\begin{tabular}{|c|c|c|c|c|c|c|c|c|c|c|}
\hline $\begin{array}{l}\text { CMCS } \\
\text { Conc. } \\
\text { wt. } \%\end{array}$ & $\begin{array}{l}\text { PEO } \\
\text { Conc. } \\
\text { wt. } \%\end{array}$ & $\begin{array}{c}\text { CMCS/PEO } \\
\text { Ratio\% } \\
\text { (wt./wt.) }\end{array}$ & $\begin{array}{l}\text { Flow } \\
\text { rate } \\
(\mathrm{mL} / \mathrm{h})\end{array}$ & $\begin{array}{l}\text { Optimal } \\
\text { voltage } \\
(\mathrm{kV})\end{array}$ & $\begin{array}{l}\text { Distance } \\
(\mathrm{cm})\end{array}$ & $\begin{array}{c}\text { Relative } \\
\text { Humidity } \\
\%\end{array}$ & $\begin{array}{c}\text { Jet } \\
\text { stability }\end{array}$ & Nanofibers & Drops & Beads \\
\hline 2.5 & 1.5 & $2: 1$ & 0.001 & 8 & 12 & 32 & - & + & - & \pm \\
\hline 2.5 & 1.5 & $1: 3$ & 0.01 & 10 & 10 & 35 & - & \pm & + & - \\
\hline 2.5 & 1.5 & $3: 1$ & 0.01 & 8 & 10 & 35 & - & \pm & \pm & - \\
\hline 2.5 & 1.5 & $3: 4$ & 0.01 & 12 & 12 & 41 & \pm & \pm & + & \pm \\
\hline 2.5 & 1.5 & $1: 4$ & 0.3 & 12 & 12 & 35 & - & + & + & - \\
\hline 2.5 & 1.5 & $4: 3$ & 0.01 & 10 & 13 & 36 & - & - & + & - \\
\hline 2.5 & 1.5 & $4: 1$ & 0.3 & 13 & 12 & 36 & - & - & + & - \\
\hline 2.5 & 3 & $2: 1$ & 0.002 & 6 & 10 & 48 & \pm & + & - & \pm \\
\hline 2.5 & 3 & $1: 3$ & 0.001 & 7 & 12 & 35 & - & \pm & + & \pm \\
\hline 2.5 & 3 & $3: 1$ & 0.2 & 6 & 11 & 53 & + & $+^{*}$ & - & - \\
\hline 2.5 & 3 & $3: 4$ & 0.001 & 7 & 12 & 36 & - & \pm & - & \pm \\
\hline 2.5 & 3 & $1: 4$ & 0.002 & 8 & 11 & 35 & - & \pm & - & \pm \\
\hline 2.5 & 3 & $4: 3$ & 0.1 & 7 & 10 & 44 & + & $+^{*}$ & - & - \\
\hline 2.5 & 3 & $4: 1$ & 0.03 & 6 & 10 & 35 & - & $+^{*}$ & - & - \\
\hline 3.3 & 3 & $2: 1$ & 0.01 & 13 & 12 & 42 & - & \pm & - & + \\
\hline 3.3 & 3 & $1: 3$ & 0.3 & 10 & 15 & 40 & + & - & - & + \\
\hline 3.3 & 3 & $3: 1$ & 0.001 & 11 & 11 & 41 & - & - & + & - \\
\hline 3.3 & 3 & $3: 4$ & 0.002 & 11 & 11 & 33 & - & - & - & + \\
\hline 3.3 & 3 & $1: 4$ & 0.03 & 10 & 11 & 36 & \pm & - & - & + \\
\hline 3.3 & 3 & $4: 3$ & 0.001 & 11 & 11 & 41 & + & - & - & - \\
\hline 3.3 & 3 & $4: 1$ & 0.001 & 13 & 12 & 42 & - & \pm & - & - \\
\hline 8 & 1.5 & $2: 1$ & 0.03 & 8 & 11 & 45 & + & $+^{*}$ & + & + \\
\hline 8 & 1.5 & $1: 3$ & 0.001 & 11 & 13 & 40 & - & \pm & - & - \\
\hline 8 & 1.5 & $3: 1$ & 0.002 & 10 & 10 & 44 & + & \pm & - & - \\
\hline 8 & 1.5 & $3: 4$ & 0.01 & 8 & 11 & 41 & \pm & - & + & + \\
\hline 8 & 1.5 & $1: 4$ & 0.005 & 14 & 11 & 42 & + & - & - & + \\
\hline 8 & 1.5 & $4: 3$ & 0.001 & 10 & 10 & 44 & + & \pm & - & \pm \\
\hline 8 & 1.5 & $4: 1$ & 0.02 & 11 & 12 & 40 & + & \pm & \pm & \pm \\
\hline 3.3 & 8 & $2: 1$ & 0.002 & 11 & 10 & 40 & + & - & - & + \\
\hline 3.3 & 8 & $1: 3$ & 0.001 & 12 & 11 & 33 & + & \pm & - & \pm \\
\hline 3.3 & 8 & $3: 1$ & 0.02 & 11 & 11 & 34 & + & \pm & - & + \\
\hline 3.3 & 8 & $3: 4$ & 0.003 & 10 & 10 & 41 & + & \pm & - & - \\
\hline 3.3 & 8 & $1: 4$ & 0.008 & 12 & 11 & 41 & + & \pm & - & \pm \\
\hline 3.3 & 8 & $4: 3$ & 0.001 & 12 & 12 & 43 & + & \pm & - & + \\
\hline 3.3 & 8 & $4: 1$ & 0.007 & 6 & 10 & 41 & + & \pm & - & - \\
\hline
\end{tabular}

Legend: $(+)$ Positive result, $(-)$ Negative result, $( \pm)$ Moderate result, $\left({ }^{*}\right)$ Optimal conditions and parameters for nanofiber formation. 